Carbohydrate Research, 195 (1990) 187-197

Elsevier Science Publishers B.V., Amsterdam - Printed in The Netherlands

\title{
CONFORMATIONAL FEATURES OF C-GLYCOSYL COMPOUNDS: CRYSTAL STRUCTURE AND MOLECULAR MODELLING OF "METHYL C-GENTIOBIOSIDE"
}

\author{
alain Neuman, François longchambon, Oukacha Abbes, Héleme Gillier-Pandraud*, \\ Laboratoire de Chimie Structurale Biomoléculaťre, U.F.R. Santé, Médecine, Biologie Humaine, \\ Université de Paris-Nord, 74 rue Marcel Cachin F-93012 Bobigny (France) \\ Serge Pérez, \\ Laboratoire de Physico-Chimie des Macromolécules, I.N.R.A., rue de la Géraudière, F-44072 Nantes \\ (France)
}

Dominique Rouzaud and Pierre Sinay

Laboratoire de Chimie, Ecole Normale Supérieure, 24 rue Lhomond, F-75005, Paris (France)

(Received March 3rd, 1989; accepted for publication, June 24th, 1989)

\section{ABSTRACT}

The crystal of "methyl $C$-gentiobioside" (methyl 8,12-anhydro-6,7-dideoxyD-glycero-D-gulo- $\alpha$-D-gluco-tridecapyranoside) $\left(\mathrm{C}_{14} \mathrm{H}_{26} \mathrm{O}_{10}\right)$ is triclinic, space group $P 1$, with $a=1.0181$ (6) nm, $b=0.8093(5) \mathrm{nm}, c=0.5066$ (4) nm, $\alpha=96.03(5)^{\circ}$, $\beta=99.94(5)^{\circ}, \gamma=90.85(5)^{\circ}$. The two $\mathrm{D}$-glucose residues have the ${ }^{4} C_{1}$ conformation. The orientation of the $\beta-(1 \rightarrow 6)$ linkage is characterized by torsion angles $\Phi=$ $55.9^{\circ}, \Psi=175.1^{\circ}$, and $\Omega=-63.9^{\circ}$. The orientation of the primary hydroxyl group at the non-reducing residue is gauche-trans $\left(\Omega^{\prime}=-53.6^{\circ}\right)$. There is no intramolecular hydrogen bond. Molecules are held together by a network of hydrogen bonds involving all of the hydroxyl groups. This crystal structure is the first experimental characterization of a " $C$-disaccharide". Unlike methyl gentiobioside, which has a high level of conformational flexibility, the " $C$-disaccharide" has a restricted flexibility. Each of the low-energy conformers in vacuo has a value of $\Phi$ centered about $60^{\circ}$, in agreement with the solid state conformation, and the exo-anomeric effect is no longer predominant.

\section{INTRODUCTION}

The biological importance of $C$-nucleosides has stimulated a search for routes of synthesis of $C$-glycosyl compounds ${ }^{1}$. Disaccharide derivatives are now available in which the inter-residue oxygen atom is replaced by a methylene group. Such $C$-linked oligosaccharides may function as active-site-directed inhibitors of en-

*Author for correspondence. 
zymes $^{2}$ and are used in the study of sugar-protein interactions ${ }^{3}$. Also, they provide a unique opportunity to evaluate the contribution of the exo-anomeric effect on the conformational preference of an oligosaccharide.

The first " $C$-disaccharide" synthesised was methyl 8,12-anhydro-6,7-dideoxyD-glycero-D-gulo- $\alpha$-D-gluco-tridecapyranoside ${ }^{4}$ ("methyl $C$-gentiobioside") in which the bridging oxygen atom of the $\beta-(1 \rightarrow 6)$ linkage was replaced by a methylene group. The present work describes the conformational features displayed by such a molecule in the solid state and a comparison with gentiobiose ${ }^{5}$.

\section{EXPERIMENTAL}

$X$-Ray investigation. - Crystals suitable for X-ray investigations were grown by cooling an ethanolic solution. Cell parameters were refined from diffractometer measurements of 25 well-centered, high-angle reflections. These and other pertinent crystal data are given in Table I. Intensity data were collected in the $\theta-2 \theta$ scan mode, by using $\mathrm{Cu} K_{\alpha}$ radiation, on a Philips PW 1100 diffractometer.

The intensities of reference reflections measured every $2 \mathrm{~h}$ did not decrease significantly during collection of the data. The data were corrected for Lorentz and polarization effects. No absorption correction was employed. Of the 3122 independent refiections measured, 1496 with $I / \sigma(I)>2$ were used for structural analysis.

The structure was solved by direct methods using the DEVIN program ${ }^{6}$. The molecule of "methyl $C$-gentiobioside" displays a pseudo center of symmetry which influenced the statistics of the normalized structure factors, and perturbed the first steps of the structure solution.

Following several cycles of full matrix, anisotropic, least-squares refinement for the non-hydrogen atoms, with the SHELX ${ }^{7}$ refinement section, the hydrogen atoms were located approximately on successive difference Fourier syntheses. They were submitted to complete refinement with isotropic thermal parameters.

The quantity minimized was $\mathrm{w}\left(F_{\mathrm{o}}-F_{\mathrm{c}}\right)^{2}$, each refiection being assigned a weight $\mathrm{w}=1 / \sigma^{2}(F)$ derived from $\sigma(I)$. A final electron-density map showed no

TABLE I

CRYSTAL DATA FOR “METHYL C-GENTIOBIOSIDE”

\begin{tabular}{ll}
\hline Formula & $\mathrm{C}_{14} \mathrm{H}_{26} \mathrm{O}_{10}$ \\
\hline Mol.wt. & 354 \\
\hline$a 1.0181(6) \mathrm{nm} ;$ & $\alpha 96.03(5)^{\circ}$ \\
$b 0.8093(5) \mathrm{nm} ;$ & $\beta 99.95(5)^{\circ}$ \\
$c 0.5066(4) \mathrm{nm} ;$ & $\gamma 90.85(5)^{\circ}$ \\
Space group & $P 1$ \\
$Z=1$ & 0.408 \\
$V\left(\mathrm{~nm}^{3}\right)$ & $1.439 \mathrm{g.cm}^{-3}$ \\
$D_{c}$ &
\end{tabular}

TABLE II

ATOMIC POSITION

Atom

C-1

C-2

C-3

C-4

C-5

C-6

C-7

C-16

O-1

O-2

O-3

O-4

O-5

C-1'

C-2'

C-3'

C-4'

C- $5^{\prime}$

C-6

O-2'

O-3'

O-4

$0-5^{\prime}$

O-6'

${ }^{\circ} U_{\mathrm{eq}}=1 / 3 \Sigma_{\mathrm{i}} \Sigma_{\mathrm{j}} \mathrm{L}$

significant resi tively. The fin dinates, a tab anisotropic, th

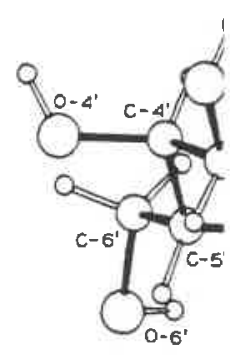

Fig. 1. Molecula structure.

*These data have B.B.A. Data Dep №. BBA/DD/421 


\section{A. NEUMAN et al.}

Also, they provide meric effect on the

hydro-6,7-dideoxy(entiobioside") in vas replaced by a ional features disith gentiobiose ${ }^{5}$.

ations were grown om diffractometer ind other pertinent 1 in the $\theta-2 \theta$ scan neter.

a did not decrease :d for Lorentz and the 3122 indepenuctural analysis.

IN program ${ }^{6}$. The if symmetry which perturbed the first

quares refinement on, the hydrogen ir syntheses. They rameters.

being assigned a ' map showed no
CRYSTAL STRUCTURE OF "METHYL C-GENTIOBIOSIDE"

TABLE II

ATOMIC POSITIONAL PARAMETERS (AND THEIR E.S.D. VALUES IN PARENTHESES)

\begin{tabular}{|c|c|c|c|c|}
\hline Atom & $\mathrm{x} / \mathrm{a}$ & $y / b$ & $z / c$ & $\mathrm{U}_{2 q}{ }^{a}$ \\
\hline C-1 & $-0.4071(2)$ & $-1.3220(3)$ & $-0.2714(6)$ & $0.031(3)$ \\
\hline C-2 & $-0.5383(2)$ & $-1.2573(3)$ & $-0.2146(5)$ & $0.030(3)$ \\
\hline C-3 & $-0.5720(2)$ & $-1.0985(3)$ & $-0.3459(6)$ & $0.029(2)$ \\
\hline$C-4$ & $-0.4560(2)$ & $-0.9723(3)$ & $-0.2489(6)$ & $0.031(3)$ \\
\hline C-5 & $-0.3263(2)$ & $-1.0466(3)$ & $-0.3122(5)$ & $0.028(2)$ \\
\hline$C-6$ & $-0.2038(2)$ & $-0.9327(3)$ & $-0.2142(6)$ & $0.029(2)$ \\
\hline C-7 & $-0.3259(4)$ & $-1.4908(4)$ & $-0.6152(8)$ & $0.098(5)$ \\
\hline C-16 & $-0.1788(2)$ & $-0.8751(3)$ & $0.0883(5)$ & $0.027(2)$ \\
\hline O-1 & $-0.4204(2)$ & $-1.3735(2)$ & $-0.5452(4)$ & $0.036(2)$ \\
\hline $0-2$ & $-0.6409(2)$ & $-1.3832(2)$ & $-0.2923(4)$ & $0.040(2)$ \\
\hline $0-3$ & $-0.6913(2)$ & $-1.0331(3)$ & $-0.2671(4)$ & $0.044(2)$ \\
\hline $0-4$ & $-0.4735(2)$ & $-0.8207(3)$ & $-0.3607(6)$ & $0.053(3)$ \\
\hline $0-5$ & $-0.3027(1)$ & $-1.1980(2)$ & $-0.1815(4)$ & $0.030(2)$ \\
\hline $\mathrm{C}-1^{\prime}$ & $-0.0489(2)$ & $-0.7730(3)$ & $0.1859(5)$ & $0.026(2)$ \\
\hline$C-2^{\prime}$ & $0.0765(2)$ & $-0.8723(3)$ & $0.1685(5)$ & $0.025(2)$ \\
\hline$C-3^{\prime}$ & $0.2006(2)$ & $-0.7599(3)$ & $0.2367(5)$ & $0.026(2)$ \\
\hline$C-4^{\prime}$ & $0.1874(2)$ & $-0.6123(3)$ & $0.0739(5)$ & $0.025(2)$ \\
\hline C. $5^{\prime}$ & $0.0595(2)$ & $-0.5235(3)$ & $0.1130(5)$ & $0.029(2)$ \\
\hline C-6' & $0.0346(3)$ & $-0.3749(3)$ & $-0.0422(7)$ & $0.052(3)$ \\
\hline $\mathrm{O}-2^{\prime}$ & $0.0873(2)$ & $-0.9930(2)$ & $0.3581(4)$ & $0.038(2)$ \\
\hline $0-3^{\prime}$ & $0.3180(2)$ & $-0.8497(2)$ & $0.2131(4)$ & $0.041(2)$ \\
\hline $\mathrm{O} \mathbf{4}^{\prime}$ & $0.3001(2)$ & $-0.5029(2)$ & $0.1654(4)$ & $0.039(2)$ \\
\hline $0-5^{\prime}$ & $-0.0521(1)$ & $-0.6358(2)$ & $0.0288(4)$ & $0.031(2)$ \\
\hline $0-6^{\prime}$ & $-0.0490(2)$ & $-0.2626(2)$ & $0.0837(5)$ & $0.049(2)$ \\
\hline
\end{tabular}

${ }^{a} U_{e q}=1 / 3 \Sigma_{i} \Sigma_{j} U_{i j} a^{*}{ }^{*} a^{*}{ }^{*} a_{i} \cdot a_{j}$.

significant residual density. The final $R$ and $R_{\mathrm{w}}$ values were 0.036 and 0.032 , respectively. The final atomic coordinates are listed in Table II. The hydrogen-atom coordinates, a tabulation of observed and calculated structure factors, and the final anisotropic, thermal parameters are available as supplementary materials*.

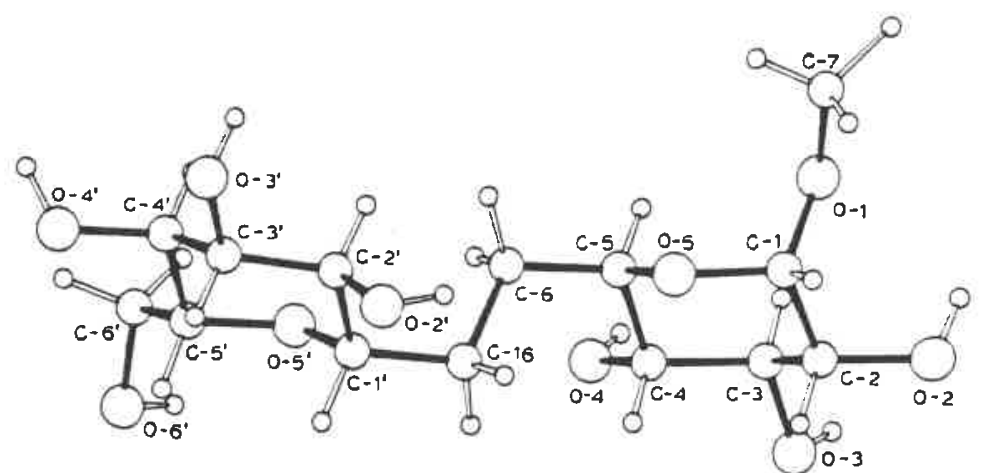

Fig. 1. Molecular conformation (ORTEPII) of "methyl C-gentiobioside" as found in the crystal structure.

"These data have been deposited with, and may be obtained from Elsevier Science Publishers B.V., B.B.A. Data Deposition, P.O. Box 1527. Amsterdam, The Netherlands. Reference should be made to No. BBAVDD/421/Carbohydr. Res., 195 (1990) 187-197. 
Conformational analysis. - The numbering of the atoms, shown in Fig. 1,

TABLE IV proceeds from the non-reducing end (primed atoms, ring II) to the reducing end (unprimed atoms, ring I). The conformational analysis to determine the likely orientation about the inter-residue junction was conducted using the program PFOS $^{8}$. The potential energy was calculated by including the partitioned contributions arising from the van der Waals, torsional, and hydrogen-bond contributions. The van der Waals interactions were evaluated by using 6-12 potential functions with the parameters proposed by Scott and Scheraga". For "methyl $C$-gentiobisiode", a three-fold, sinusoidal potential was used for rotation about torsion angles $\Phi$ and $\Psi$, with a barrier of $3.5 \mathrm{kcal} . \mathrm{mol}^{-1}$ for the eclipsed orientation. As for gentiobiose, a barrier of $1.0 \mathrm{kcal} . \mathrm{mol}^{-1}$ was assigned to the eclipsed orientation around $\Psi$. For rotation about the glycosidic angle $\Phi$, the intramolecular mechanism responsible for the exo-anomeric effect was taken into account by using the potential function proposed by Tvaroska ${ }^{10}$; a sinusoidal, three-fold, eclipsed, rotational barrier of $1.0 \mathrm{kcal} . \mathrm{mol}^{-1}$ was also included. The hydrogen-bond energy was computed by an empirical expression proposed by Pérez and Vergelati ${ }^{11}$. In these calculations, the hydroxylic hydrogen atoms were not considered, and the geometry of each residue was considered to be rigid. No electrostatic interaction was taken into account.

\section{RESULTS AND DISCUSSION}

A representation (ORTEP ${ }^{12}$ ) of the molecule of "methyl $C$-gentiobioside" is shown in Fig. 1. The bond distances and angles are given in Tables III and IV, respectively.

Molecular features. - The bond distances and angles observed in this crystal structure compare well with those for gentiobiose ${ }^{5}$, and conform to the tabulated values of carbohydrates ${ }^{13}$. The expected ${ }^{4} C_{1}$ chair conformation was found for the TABLE III

BOND DISTANCES ${ }^{\circ}$ (NM) AND THEIR E.S.D. VALUES

\begin{tabular}{llll}
\hline C-1-C-2 & $0.1505(4)$ & $C-1^{\prime}-C-2^{\prime}$ & $0.1530(3)$ \\
C-1-O-1 & $0.1389(3)$ & $C-16-C-1^{\prime}$ & $0.1527(3)$ \\
C-1-O-5 & $0.1432(3)$ & $C-1^{\prime}-O^{\prime}$ & $0.1430(3)$ \\
C-2-C-3 & $0.1525(4)$ & $C-2^{\prime}-C-3^{\prime}$ & $0.1514(3)$ \\
C-2-O-2 & $0.1424(3)$ & $C-2^{\prime}-O-2^{\prime}$ & $0.1432(3)$ \\
C-3-C-4 & $0.1529(4)$ & $C-3^{\prime}-C-4^{\prime}$ & $0.1516(3)$ \\
C-3-O-3 & $0.1434(3)$ & $C-3^{\prime}-O-3^{\prime}$ & $0.1424(3)$ \\
C-4-C-5 & $0.1528(3)$ & $C-4^{\prime}-C-5^{\prime}$ & $0.1529(3)$ \\
C-4-O-4 & $0.1406(3)$ & $C-4^{\prime}-O-4^{\prime}$ & $0.1420(3)$ \\
C-5-C-6 & $0.1520(4)$ & $C-5^{\prime}-C-6^{\prime}$ & $0.1506(4)$ \\
C-5-O-5 & $0.1456(3)$ & $C-5^{\prime}-O-5^{\prime}$ & $0.1421(3)$ \\
C-6-C-16 & $0.1531(4)$ & & \\
C-7-O-1 & $0.1424(4)$ & & \\
\hline
\end{tabular}

${ }^{a}$ Mean bond lengths: C-H, 0.110; O-H, $0.091 \mathrm{~nm}$.

BOND ANGLES

$\mathrm{C}-2-\mathrm{C}-1-\mathrm{O}-1$

$\mathrm{C}-2-\mathrm{C}-1-\mathrm{O}-\mathrm{-}-5$

O-5-C-1-O-1

$\mathrm{C}-1-\mathrm{C}-2-\mathrm{C}-3$

$\mathrm{C}-1-\mathrm{C}-2-\mathrm{O}-2$

$\mathrm{C}-3-\mathrm{C}-2-\mathrm{O}-2$

$\mathrm{C}-2-\mathrm{C}-3-\mathrm{C}-4$

C. $-2-\mathrm{C}-3-\mathrm{O}-3$

$\mathrm{C}-4-\mathrm{C}-3-\mathrm{O}-3$

C-3-C-4-C-5

C. $3-\mathrm{C}-4-\mathrm{O}-4$

$\mathrm{C}-5-\mathrm{C}-4-\mathrm{O}-4$

C. $4-\mathrm{C}-5-\mathrm{C}-6$

C-4-C-5-0-5

C- $6-C-5-0-5$

C-5-C-6-C-16

C-1-0.5-C-5

C-6-C-16-C-1

$\mathrm{C}-1-\mathrm{O}-1-\mathrm{C}-7$

pyranose re given in $\mathrm{Ta}$ "methyl $C_{-!}$ extreme var similar conc can be dra "methyl $C$-g The $C$ refiects the $\mathrm{i}$ The o

TABLE V

TORSION ANGLE

Ring I

O-5-C-1-C-2C-1-C-2-C-3-C C-2-C-3-C-4-C $\mathrm{C}-3-\mathrm{C}-4-\mathrm{C}-5-\mathrm{C}$ C. $4-\mathrm{C}-5-0-5-$ C-5-0-5-C-1-

Mean absolute

${ }^{\circ}$ E.s.d., 0.2 ${ }^{\circ}$ 
TABLE IV

BOND ANGLES $\left({ }^{\circ}\right.$ ) AND THEIR E.S.D. VALUES

\begin{tabular}{|c|c|c|c|c|}
\hline C-2-C-1-O-1 & $108.6(2)$ & $C-2^{\prime}-C-1^{\prime}-C-16$ & $113.8(2)$ & 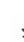 \\
\hline$C-2-C-1-0-5$ & $110.5(2)$ & $\mathrm{C}-2^{\prime}-\mathrm{C}-1^{\prime}-\mathrm{O}-5^{\prime}$ & $110.5(2)$ & \\
\hline $0-5-C-1-0-1$ & $112.3(2)$ & $0-5^{\prime}-C-1^{\prime}-C-16$ & $107.5(2)$ & \\
\hline$C-1-C-2-C-3$ & $111.2(2)$ & $\mathrm{C}-1^{\prime}-\mathrm{C}-2^{\prime}-\mathrm{C}-3^{\prime}$ & $111.0(2)$ & 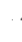 \\
\hline $\mathrm{C}-1-\mathrm{C}-2-\mathrm{O}-2$ & $110.5(2)$ & $\mathrm{C}-1^{\prime}-\mathrm{C}-2^{\prime}-\mathrm{O}-2^{\prime}$ & $109.3(2)$ & \\
\hline $\mathrm{C}-3-\mathrm{C}-2-\mathrm{O}-2$ & $112.6(2)$ & $\mathrm{C}-3^{\prime}-\mathrm{C}-2^{\prime}-\mathrm{O}-2^{\prime}$ & $108.1(2)$ & \\
\hline C-2-C-3-C-4 & $108.3(2)$ & $C-2^{\prime}-C-3^{\prime}-C-4^{\prime}$ & $111.3(2)$ & \\
\hline C- $2-C-3-0-3$ & $109.3(2)$ & $\mathrm{C}-2^{\prime}-\mathrm{C}-3^{\prime}-\mathrm{O}-3^{\prime}$ & $111.7(2)$ & \\
\hline$C-4-C-3-0-3$ & $109.7(2)$ & $C-4^{\prime}-C-3^{\prime}-0.3^{\prime}$ & $112.7(2)$ & \\
\hline$C-3-C-4-C-5$ & $109.0(2)$ & $C-3^{\prime}-C-4^{\prime}-C-5^{\prime}$ & $108.9(2)$ & \\
\hline$C-3-C-4-O-4$ & $113.9(2)$ & $C-3^{\prime}-\mathrm{C}-4^{\prime}-0-4^{\prime}$ & $108.8(2)$ & \\
\hline C-5-C-4-O-4 & $108.8(2)$ & $C-5^{\prime}-\mathrm{C}-4^{\prime}-\mathrm{O}-4^{\prime}$ & $110.2(2)$ & \\
\hline$C-4-C-5-C-6$ & $114.0(2)$ & $C-4^{\prime}-\mathrm{C}-5^{\prime}-\mathrm{C}-6^{\prime}$ & $113.9(2)$ & \\
\hline$C-4-C-5-0-5$ & $109.2(2)$ & $C-4^{\prime}-C-5^{\prime}-O-5^{\prime}$ & $109.6(2)$ & \\
\hline C- $6-C-5-0-5$ & $106.9(2)$ & C- $6^{\prime}-\mathrm{C}-5^{\prime}-0-5^{\prime}$ & $107.6(2)$ & \\
\hline C-5-C-6-C-16 & $114.7(2)$ & $C-5^{\prime}-C-6^{\prime}-0-6^{\prime}$ & $109.9(2)$ & \\
\hline$C-1-0-5-C-5$ & $112.8(2)$ & $C-1^{\prime}-0-5^{\prime}-C-5^{\prime}$ & $113.2(2)$ & \\
\hline C-6-C-16-C-1' & $113.6(2)$ & & & \\
\hline $\mathrm{C}-1-0-1-\mathrm{C}-7$ & $114.8(2)$ & & & \\
\hline
\end{tabular}

pyranose residues, and the torsion angles about the skeletal bonds of the rings are given in Table $\mathrm{V}$. The mean values of the intracyclic torsion angles in ring I of "methyl $C$-gentiobioside" and gentiobiose are $57.8^{\circ}$ and $57.6^{\circ}$, respectively. The extreme variations are $55.4^{\circ}-60.5^{\circ}$ for the former and $49.7^{\circ}-64.7^{\circ}$ for the latter. A similar conclusion about the rigidity of the residues in "methyl $C$-gentiobioside" can be drawn; for ring II, the mean absolute values are $56.5^{\circ}\left(51.2^{\circ}-63.2^{\circ}\right)$ in "methyl $C$-gentiobioside", and $55.4^{\circ}\left(49.2^{\circ}-66.4^{\circ}\right)$ in gentiobiose.

The $0-1$ Me group is in a gauche orientation with respect to $0-5$, which reflects the influence of the exo-anomeric effect ${ }^{14}$.

The orientation of the HO-6 is usually defined as gauche-gauche, gauche-

TABLE V

TORSION ANGLES $\left({ }^{\circ}\right)^{a}$

\begin{tabular}{|c|c|c|c|}
\hline \multicolumn{2}{|l|}{ Ring I } & \multicolumn{2}{|l|}{ Ring II } \\
\hline $\mathrm{O}-5-\mathrm{C}-1-\mathrm{C}-2-\mathrm{C}-3$ & 56.9 & $0-5^{\prime}-\mathrm{C}-1^{\prime}-\mathrm{C}-2^{\prime}-\mathrm{C}-3^{\prime}$ & 52.3 \\
\hline C. $1-C-2-C \cdot 3-C-4$ & -55.4 & $C-1^{\prime}-C-2^{\prime}-C-3^{\prime}-C-4^{\prime}$ & -51.2 \\
\hline$C-2-C-3-C-4-C-5$ & 56.2 & $C-2^{\prime}-C-3^{\prime}-C-4^{\prime}-C-5^{\prime}$ & 53.9 \\
\hline$C-3-C-4-C-5-0-5$ & -58.4 & $\mathrm{C}-3^{\prime}-\mathrm{C}-4^{\prime}-\mathrm{C}-5^{\prime}-\mathrm{O}-5^{\prime}$ & -58.8 \\
\hline$C-4-C-5-0-5-C-1$ & 60.5 & $C-4^{\prime}-C-5^{\prime}-O-5^{\prime}-C-1^{\prime}$ & 63.2 \\
\hline$C-5-0-5-C-1-C-2$ & -59.7 & $C-5^{\prime}-0.5^{\prime}-\mathrm{C}-1^{\prime}-\mathrm{C}-2^{\prime}$ & -59.6 \\
\hline \multicolumn{4}{|c|}{ Mean absolute values: } \\
\hline
\end{tabular}

${ }^{a}$ E.s.d., $0.2^{\circ}$ 


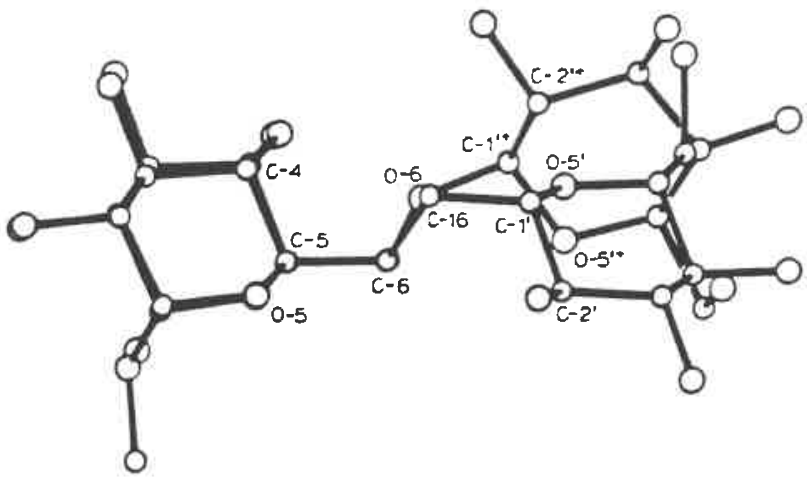

TABLE V

HYDROGEN

$0.2 \ldots$

O-2...

$\mathrm{H}-\mathrm{O}-2 \ldots$

0.3...

O-3...

1

$\mathrm{H}-\mathrm{O}-3$.

O-4-H-O-4

Fig. 2. Comparison between the solid state conformation of "methyl C-gentiobioside" and gentiobiose.

trans, or trans-gauche ${ }^{15}$. In this terminology, the torsion angle (O-5-C-5-C-6-O-6) is stated first, and the torsion angle (C-4-C-5-C-6-O-6) second. For the gluco configuration, the orientations observed in the solid state are usually almost equally distributed between gauche-gauche and gauche-trans ${ }^{14}$. In the present molecule, the orientation of HO- $6^{\prime}$ i.e., about C-5'-C-6', is in a gauche-gauche conformation $\left(-53.6^{\circ}\right)$. A gauche-trans conformation $\left(66.1^{\circ}\right)$ was found for gentiobiose.

In the "methyl $C$-gentiobioside" molecule, a pseudo-inversion center is located between C-6 and C-16 (mean coordinates $=0.1817,-0.9249,-0.0597$ ).

The relative orientation of two residues connected by a $(1 \rightarrow 6)$ linkage is given by the torsional angles: $\Phi 0-5^{\prime}-C-1^{\prime}-C-16-C-6, \Psi$ C-1'-C-16-C-6-C-5, and $\Omega$ C16-C-6-C-5-O-5. For both "methyl $C$-gentiobioside" and gentiobiose, the conformations about $\Omega$ are similar $\left[\Omega=-64.0(2)^{\circ}\right.$ and $-61.5(5)^{\circ}$, respectively], and correspond to a gauche-gauche type orientation. Similarly, the conformation about $\Psi$ is almost perfectly trans $\left[175.1(2)^{\circ}\right]$ in "methyl $C$-gentiobioside", which is $29^{\circ}$ away from the conformation $\left(-156.3^{\circ}\right)$ for gentiobiose. A drastic difference, see Fig. 2, of $\sim 120^{\circ}$ is found for $\Phi$ for the linkage conformation of the two molecules (55.9 $9^{\circ}$ in the $C$-glycoside, versus $-58.3^{\circ}$ in the $O$-glycoside).

Hydrogen bonding and packing. - The crystal structure of "methyl $C$-gentiobioside" involves an extensive network of hydrogen bonds, described in Table VI, a projection of which is shown in Fig. 3. All the hydroxyl oxygen atoms participate in hydrogen bonds ( $76.5 \%$ as both donor and acceptor, and $12.4 \%$ as donor only) and they follow the pattern proposed by Avene ${ }^{16}$. Moreover, the molecules adopt an optimum mode of packing. All the non-polar groups $\left(\mathrm{CH}_{3}, \mathrm{CCH}_{2} \mathrm{C}\right)$ interact and create cylindrical hydrophobic channels which are embedded in a hydrophilic matrix where all the hydrogen bonds are located. As seen in Fig. 3, hydrophobic and hydrophilic zones are of equal importance. The crystal structure is dense, each "methyl $C$-gentiobioside" molecule being surrounded by 10 neighbors.

Molecular modelling. - In order to rationalize the observed solid-state conformation, and to compare it with that of gentiobiose, a set of iso-energy maps was computed and plotted. These maps correspond to intramolecular-energy variations 
TABLE VI

HYDROGEN BONDING (DISTANCE, NM)

" and gentiobiose.

5-C-5-C-6-O-6) I the gluco con- almost equally esent molecule, ve conformation obiose.

rsion center is $49,-0.0597$ ).

linkage is given $=\bar{C}-5$, and $\Omega$ C. sse, the conforipectively], and ormation about ", which is $29^{\circ}$ difference, see two molecules ethyl $C$-gentiod in Table VI, ims participate as donor only) rolecules adopt $\mathrm{H}_{2} \mathrm{C}$ ) interact 1 a hydrophilic i, hydrophobic is dense, each rs:

olid-state conergy maps was argy variations

\begin{tabular}{|c|c|c|c|}
\hline $0-2 \cdots$ & $\mathrm{H}-\mathrm{O}-4^{\prime}$ & 0.188 & \\
\hline $\mathrm{O}-2 \cdots$ & $\mathrm{O}-4^{\prime}$ & 0.276 & $-1,-1,0$ \\
\hline $\mathrm{H}-\mathrm{O}-2 \ldots$ & $0.4^{\prime}$ & 0.187 & $-1,-1,-1$ \\
\hline $0-3 \cdots$ & $\mathrm{H}-\mathrm{O}-3^{\prime}$ & 0.184 & \\
\hline $0-3 \cdots$ & $0-3^{\prime}$ & 0.270 & $-1,0,0$ \\
\hline $\mathrm{H}-\mathrm{O}-3 \ldots$ & $0-2^{\prime}$ & 0.173 & $-1,0,-1$ \\
\hline $\mathrm{O}-4-\mathrm{H}-\mathrm{O}-4 \cdots$ & O-3' & 0.198 & $-1,0,-1$ \\
\hline $0-5 \cdots$ & $\mathrm{H}-\mathrm{O}-6^{\prime}$ & 0.190 & \\
\hline $0-5 \cdots$ & $0-6^{\prime}$ & 0.278 & $0,-1,0$ \\
\hline $\mathrm{O}-2^{\prime} \cdots$ & $\mathrm{H}-\mathrm{O}-3$ & 0.173 & \\
\hline$\underset{1}{O}-2^{\prime} \cdots$ & $0-3$ & 0.273 & $-1,0,1$ \\
\hline $\mathrm{H}-\mathrm{O}-2^{\prime} \cdots$ & $0-6^{\prime \prime}$ & 0.188 & $0,-1,0$ \\
\hline $0-3^{\prime} \ldots$ & $\mathrm{H}-\mathrm{O}-4$ & 0.198 & \\
\hline $0-3^{\prime} \ldots$ & 0.4 & 0.274 & $1,0,0$ \\
\hline $\mathrm{H}-\mathrm{O}-3 \cdots$ & $0-3$ & 0.184 & $1,0,0$ \\
\hline O-4' $\ldots$ & $\mathrm{H}-\mathrm{O}-2$ & 0.187 & \\
\hline $0-4^{\prime} \cdots$ & $0-2$ & 0.276 & $1,1,1$ \\
\hline $\mathrm{H}-\mathrm{O}-4^{\prime} \cdots$ & $\mathrm{O}-2$ & 0.187 & $1,1,0$ \\
\hline $0-6^{\prime} \cdots$ & $\mathrm{H}-\mathrm{O}-2^{\prime}$ & 0.188 & \\
\hline $0-6^{\prime} \cdots$ & $0-2^{\prime}$ & 0.269 & $0,1,0$ \\
\hline $\mathrm{H}-\mathrm{O}-6^{\prime} \ldots$ & $0-5$ & 0.190 & $0,1,0$ \\
\hline
\end{tabular}

as a function of $\Phi$ and $\Psi$, with $\Omega$ being assigned successively one of the three non-eclipsing conformations corresponding to gauche-gauche, gauche-trans, and trans-gauche. Calculations were performed on "methyl $C$-gentiobioside" and gentiobiose, with the ring geometry found in the corresponding crystal structures. The data are summarized in Fig. 4. For "methyl $C$-gentiobioside", the potential energy surfaces computed for each of the stable conformations of $\Omega$ are comparable. There is only one low-energy domain centered about $\Phi=60^{\circ}$, which spans over $180^{\circ}$ along $\Psi$, with a well-defined three-fold symmetry. The precise locations of the low-energy conformers, along with the main contributors to the energy, are indicated in Table VII; the corresponding inter-residue hydrogen bonds, when occurring, are also listed. The calculated conformation having the lowest energy occurs for $\Phi=55^{\circ}, \Psi=180^{\circ}, \Omega=-60^{\circ}$, and $E=-4.57 \mathrm{kcal} . \mathrm{mol}^{-1}$, which is similar to that in the crystal $\left[\Phi=55.8^{\circ}, \Psi=175.1^{\circ}\right.$ (or $-184.9^{\circ}$ ), $\Omega=-63.9^{\circ}, E$ 


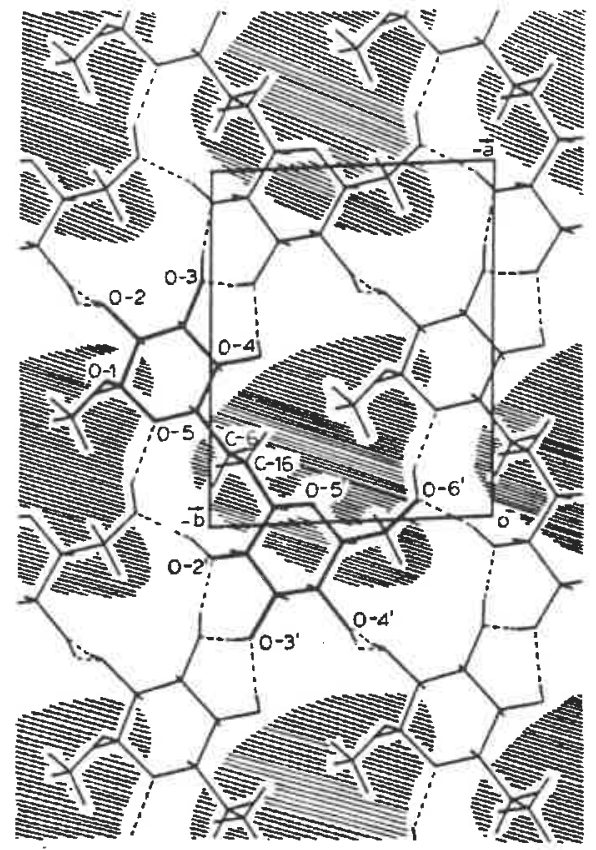

Fig. 3. Projected view of the packing of "methyl $C$-gentiobioside" in the crystallographic (a, b) plane. Hatched zones indicate the hydrophobic regions.

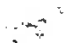

$\left.=-4.46 \mathrm{kcal}^{\prime} \mathrm{mol}^{-1}\right]$. Such good agreement indicates the suitability of the set of potential energy functions and associated parameters for the conformational analysis of $C$-glycosyl compounds.

Iso-energy surfaces were calculated for the molecule of gentiobiose for each of the stable conformations of $\Omega\left(-60^{\circ}, 60^{\circ}, 180^{\circ}\right)$ and they are represented in Fig. $4 d-f$. The low-energy domains encompass $\sim 50 \%$ of the total $(\Phi, \Psi)$ surface. Many local energy minima are found (Table VIII). The conformation found for gentiobiose in the solid state $\left(\Phi=-58.3^{\circ}, \Psi=-156.3^{\circ}, \Omega=-61.5^{\circ}, E=-1.77\right.$ $\mathrm{kcal} . \mathrm{mol}^{-1}$ ) belongs to the low-energy domain where the deepest minimum is found $\left(\Phi=-75^{\circ}, \Psi=-175^{\circ}, \Omega=-60^{\circ}, E=-2.22 \mathrm{kcal} . \mathrm{mol}^{-1}\right)$. Almost irrespective of the $\Omega$ values, two distinct regions of the $(\Phi, \Psi)$ map define the low-energy domains. The low-energy area centered around $\Phi=-80^{\circ}$, and spanning from $\Psi$ $=60^{\circ}$ to $\Psi=-60^{\circ}$, contains most of the low-energy conformers. The second more restricted domain corresponds to conformations having $\Phi$ close to $60^{\circ}$, the $\Psi$ values spanning from $\Psi=90^{\circ}$ to $\Psi=-90^{\circ}$. All the local minima belonging to this domain have energy values significantly higher than those of the other domain.

The conformation of "methyl C-gentiobioside" in solution, determined by high-resolution n.m.r. spectroscopy ${ }^{17}$, is described by $\Phi=-85^{\circ}, \Psi=180^{\circ}$, and $\Omega$ $=85^{\circ}$ (these values have been recalculated from those reported, because the authors made use of a different convention ${ }^{18}$ ). Such a conformation does not corres- 
graphic (a, b) plane.

ility of the set of conformational

tiobiose for each presented in Fig. v) surface. Many ound for gentio$.5^{\circ}, E=-1.77$ linimum is found nost irrespective : the low-energy ;panning from $\Psi$ The second more $60^{\circ}$, the $\Psi$ values ng to this domain nain.

, determined by $\Psi=180^{\circ}$, and $\Omega$ ed, because the I does not corres-
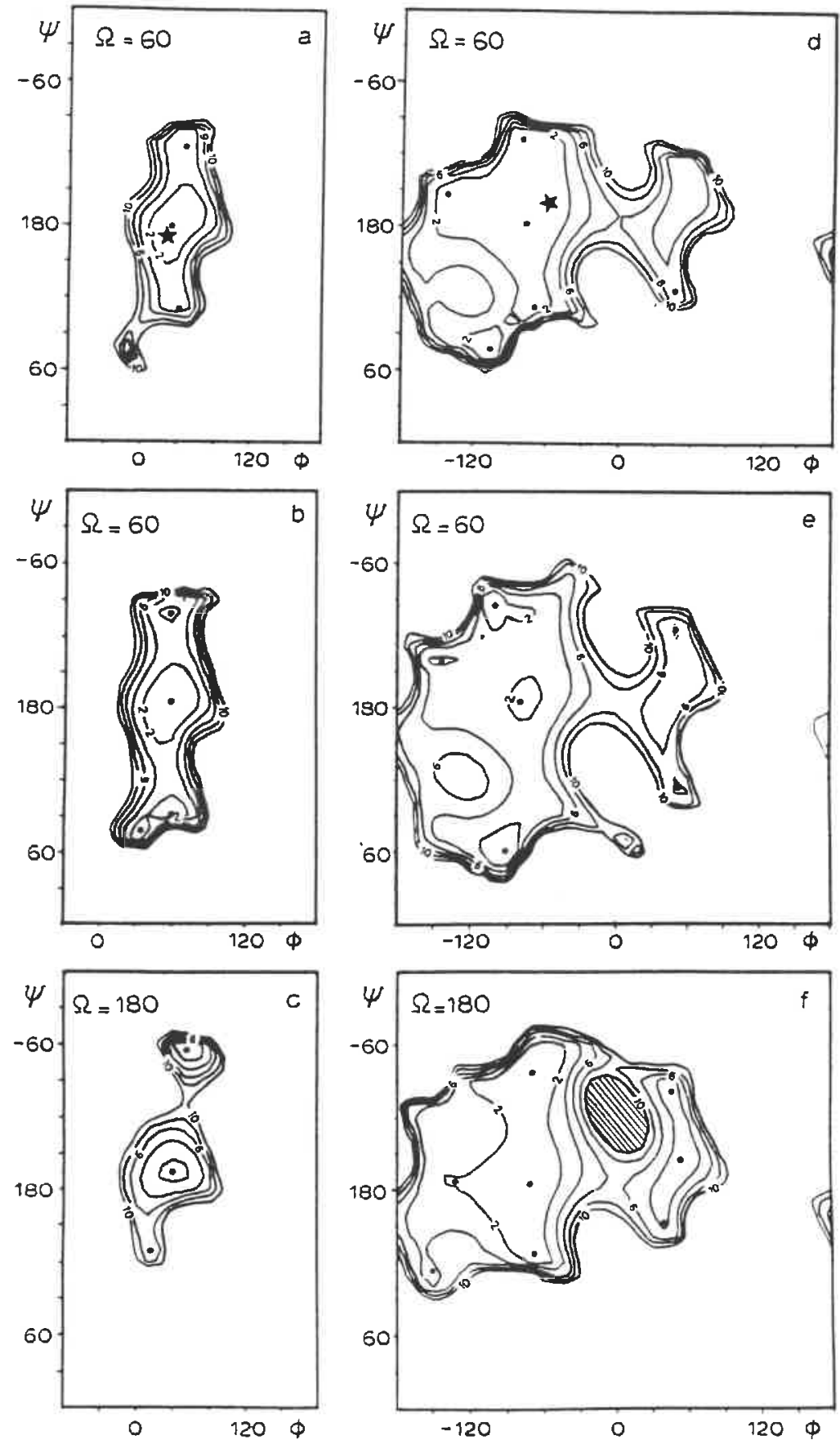

Fig. 4. Iso-energy maps $(\Phi, \Psi)$ about the $(1 \rightarrow 6)$ linkage for "methyl $C$-gentiobioside" $(a, b, c)$ and for gentiobiose $(d, e, f)$. In each case, three orientations for the torsion angle $\Omega$ were taken into account. Relative iso-energy contours are drawn at intervals of $2 \mathrm{kcal} / \mathrm{mol}$; the symbol * indicates the occurrence of the minima observed in the crystal structures. 
TABLE VII

LOW-ENERGY CONFORMERS OF "METHYL C-GENTIOBIOSIDE"

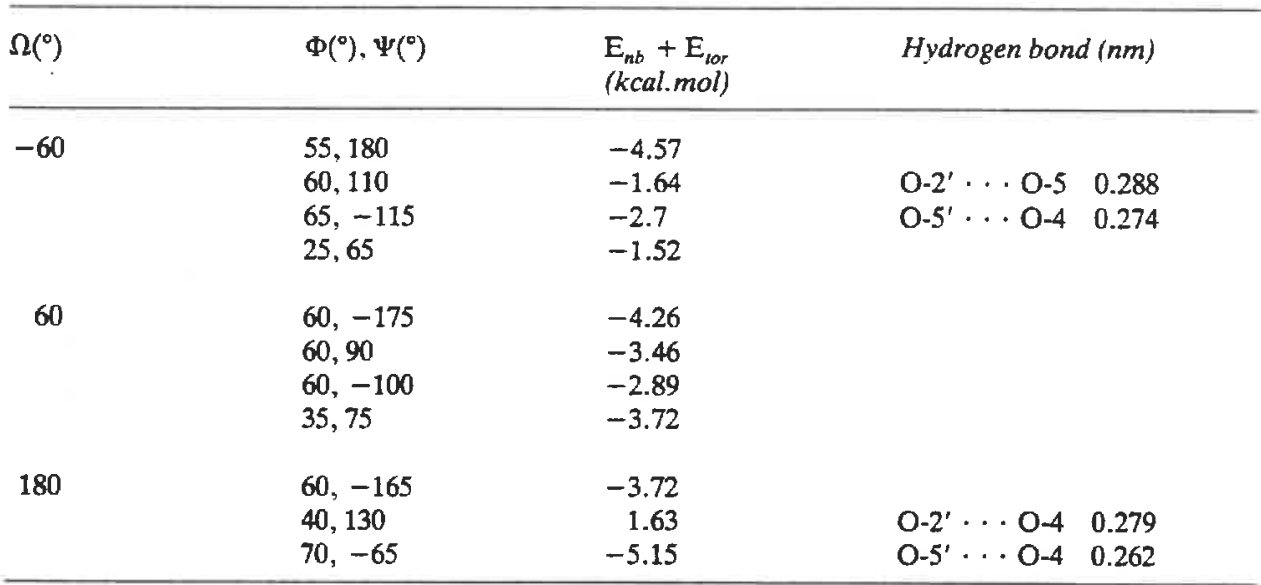

TABLE VIII

LOW-ENERGY CONFORMERS OF GENTIOBIOSE

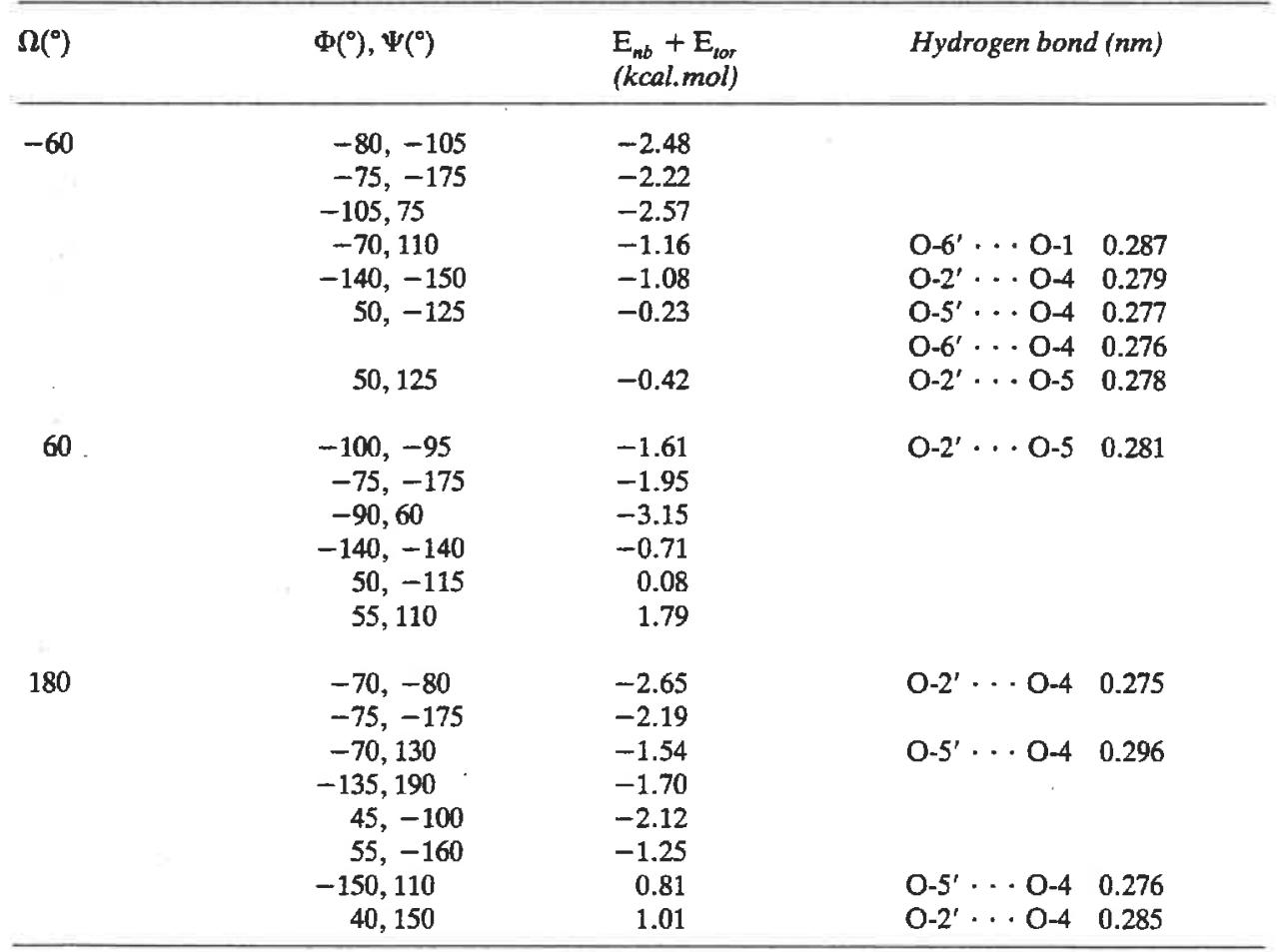

pond to any

magnitude $c$ The $p$ saccharide" of the avai analogue. $T$ $120^{\circ}$ differe tions indica saccharide" interaction 6 a bridging $\mathrm{C}$ C-16-C-6 bi biose and it:

REFERENCE

$1 \mathrm{~S}$. HANNess

2 M. L. SHU CERRETTI, $i$

3 L. A. REED

4 D. ROUZAL

5 D. C. ROH 650-654.

6 C. RICHE,

7 G. SHELDRI 1976.

8 S. Pérez, I

9 R. A. SCOT

10 I. TVAROSK

11 S. PEREZ As

12 C. K. JoHN

13 F. LONGCH

LEHMAN, As

14 F. LONGCH/

15 R. H. MARI

16 D. AVENEL:

17 P. G. GOEK

18 D. Y. GAGP 430. 
pond to any of the stable states calculated for the molecule in vacuum. The reported magnitude of $\Phi=-85^{\circ}$ lies far from the only stable values centered about $\Phi=60^{\circ}$.

The present work provides the first experimental characterization of a " $\mathrm{C}$-disaccharide" molecule. The molecular modelling study indicates a drastic decrease of the available conformational space, on going from gentiobiose to the $C$ analogue. The striking difference occurs about the $\Phi$ torsion angle, since there is a $120^{\circ}$ difference between the magnitude of this angle in both molecules. The calculations indicate that the lack of influence of the exo-anomeric effect in the " $C$-disaccharide" is not responsible for such a shift. Indeed, it results simply from steric interaction of the substituents at the inter-residue linkage. Also, the substitution of a bridging oxygen atom by a $\mathrm{CH}_{2}$ group favours a trans conformation about the C-16-C -6 bond. The conformations about the exocyclic C-6-C-5 bond of gentiobiose and its $C$-analogue are similar.

\section{REFERENCES}

1 S. Hannessian and A. G. Pernet, Adv. Carbohydr. Chem. Biochem., 33 (1976) 111-188.

2 M. L. Shuman, S. D. ShiYAN, AND A. Y. Khorlin, Carbohydr. Res., 33 (1974) 229-235; D. CerRetTI, ibid., 94 (1981) c10-c13.

3 L. A. Reed, I. Ito, S. Masamune, And K. B. Sharpless, J. Am. Chem. Soc., 104 (1982) 6468-6470.

4 D. Rouzaud and P. Sinay, J. Chem. Soc., Chem. Commun., (1983) 1353-1354.

5 D. C. Rohrer, A. Sarko, T. L. BluhM, AND Y. N. LeE, Acta Crystallogr., Sect. B, 36 (1980) 650-654.

6 C. RiCHE, Acta Crystallogr., Sect. A, 29 (1973) 133-137.

7 G. Sheldrick, SHELX, A Program for Crystal Structure Determination, University of Cambridge, 1976.

8 S. PEREZ, D.Sc. Thesis, University of Grenoble, 1978.

9 R. A. Scott and H. A. Scheraga, J. Chem. Phys., 42 (1965) 2209-2215.

10 I. TVaroska, Carbohydr. Res., 125 (1984) 1951-1960.

11 S. Pérez and C. Vergelati, Polym. Bull., 17 (1987) 141-148.

12 C. K. JOHNSON, ORTEP, Report ORNL-3794, Oak Ridge National Laboratory, Tennessee, 1965.

13 F. Longchambon, H. Gillier-Pandraud, R. Wiest, B. Rees, A. Mrtschler, R. Feld, M. Lehman, AND P. BeCKer, Acta Crystallogr., Sect. B, 41 (1985) 47-56.

14 F. Longchambon, D.Sc. Thesis, Univ. Paris-Nord, 1983.

15 R. H. Marchessault ANd S. Perez, Biopolymers, 18 (1979) $2369-2374$.

16 D. Avenel, D.Sc. Thesis, Univ. Paris-Nord, 1986.

17 P. G. GoekJian, T. C. WU, H. Y. Kang, AND Y. Kishl, J. Org. Chem., 52 (1987) $4823-4825$.

18 D. Y. Gagnaire, R. Nardin, F. R. Taravel. and M. R. Vignon, Nouv. J. Chim., 1 (1987) 423430. 